\title{
A novel CT-emphysema index/FEV, approach of phenotyping COPD to predict mortality
}

This article was published in the following Dove Press journal: International journal of COPD

\author{
Li-Cher Loh' \\ Choo-Khoon Ong' \\ Hyun-Jung Koo² \\ Sang Min Lee ${ }^{2}$ \\ Jae-Seung Lee ${ }^{3}$ \\ Yeon-Mok Oh ${ }^{3}$ \\ Joon-Beom Seo ${ }^{2}$ \\ Sang-Do Lee ${ }^{3}$ \\ 'Department of Medicine, RCSI \& \\ UCD Malaysia Campus, Penang, \\ Malaysia; ${ }^{2}$ Department of Radiology, \\ Research Institute of Radiology, Asan \\ Medical Center, University of Ulsan \\ College of Medicine, Seoul, Republic \\ of Korea; ${ }^{3}$ Department of Pulmonary \\ and Critical Care Medicine, and \\ Clinical Research Center for Chronic \\ Obstructive Airway Diseases, Asan \\ Medical Center, University of Ulsan \\ College of Medicine, Seoul, Republic \\ of Korea
}

Correspondence: Li-Cher Loh Department of Medicine, Penang Medical College, 4 Jalan Sepoy Lines, Georgetown, 10450 Penang, Malaysia Tel +6042287171

Fax +6042284285

Email richard_loh@pmc.edu.my
Background: COPD-associated mortality was examined using a novel approach of phenotyping COPD based on computed tomography (CT)-emphysema index from quantitative CT (QCT) and post-bronchodilator (BD) forced expiratory volume in 1 second $\left(\mathrm{FEV}_{1}\right)$ in a local Malaysian cohort.

Patients and methods: Prospectively collected data of 112 eligible COPD subjects (mean age, 67 years; male, 93\%; mean post-BD $\mathrm{FEV}_{1}, 45.7 \%$ ) was available for mortality analysis. Median follow-up time was 1,000 days (range, 60-1,400). QCT and clinicodemographic data were collected at study entry. Based on CT-emphysema index and post-BD FEV $\%$ predicted, subjects were categorized into "emphysema-dominant," "airway-dominant," "mild mixed airway-emphysema," and "severe mixed airway-emphysema" diseases.

Results: Sixteen patients (14.2\%) died of COPD-associated causes. There were 29 (25.9\%) "mild mixed," 23 (20.5\%) "airway-dominant," 15 (13.4\%) "emphysema-dominant," and $45(40.2 \%)$ "severe mixed" cases. "Mild mixed" disease was proportionately more in Global Initiative for Chronic Obstructive Lung Disease (GOLD) Group A, while "severe mixed" disease was proportionately more in GOLD Groups B and D. Kaplan-Meier survival estimates showed increased mortality risk with "severe mixed" disease (log rank test, $p=0.03$ ) but not with GOLD groups $(p=0.08)$. Univariate Cox proportionate hazard analysis showed that age, body mass index, long-term oxygen therapy, $\mathrm{FEV}_{1}$, forced volume capacity, COPD Assessment Test score, modified Medical Research Council score, St Georges' Respiratory Questionnaire score, CT-emphysema index, and "severe mixed" disease (vs "mild mixed" disease) were associated with mortality. Multivariate Cox analysis showed that age, body mass index, and COPD Assessment Test score remain independently associated with mortality.

Conclusion: "Severe mixed airway-emphysema" disease may predict COPD-associated mortality. Age, body mass index, and COPD Assessment Test score remain as key mortality risk factors in our cohort.

Keywords: computed tomography, emphysema, forced expiratory volume, COPD, mortality

\section{Introduction}

COPD is a leading cause of death globally. ${ }^{1}$ Its heterogeneity presents a challenge to research and pursuit of effective treatment. Many factors like airflow obstruction by spirometry, exercise capacity, frequency of exacerbation, body mass index (BMI), and comorbidities have been shown to influence prognosis. ${ }^{2}$ Since 2011, the Global Initiative for Chronic Obstructive Lung Disease (GOLD) initiative has advocated a 2-dimensional combined approach (based on symptoms and exacerbation risk/forced expiratory volume in 1 second $\left[\mathrm{FEV}_{1}\right]$ ) to classifying COPD (into Groups A-D) to guide treatment. From the 2017 guidelines, GOLD committee has removed FEV from to ease ranking. ${ }^{3}$ In recent years, quantitative computed tomography (QCT) 
is being recognized as a valuable tool of phenotyping and prognosticating COPD. ${ }^{4,5}$ All these approaches will help to prognosticate COPD with a view to recommend therapy.

Compared to the pre-2011 GOLD classification (based solely on post-bronchodilator [BD] $\mathrm{FEV}_{1}$ ), some researchers have questioned the ability of the GOLD combined approach to better predict mortality. ${ }^{6,7}$ It is unclear if the exclusion of $\mathrm{FEV}_{1}$ from GOLD combined assessment in 2017 further affects this. QCT measurement of emphysema, air-trapping, and airways in COPD has significantly improved over the years $^{8}$ and has been shown to correlate with physiologic parameters and clinical outcomes like exacerbations, quality of life, and mortality., ${ }^{4,59}$ Among the QCT measurements, CT-emphysema index is probably the most robust parameter that is least subjected to external influences like inspiratory volume and measurement biases. ${ }^{8,10}$

Lee et $\mathrm{al}^{11}$ were the first researchers who explored the use of CT-emphysema index and $\mathrm{FEV}_{1}$ to subtype COPD into 4 phenotypes of "airway-dominant," "emphysemadominant," "mild mixed airway-emphysema," and "severe mixed airway-emphysema" disease. They showed that "emphysema-dominant" subtype alone showed least improvement of $\mathrm{FEV}_{1}$ and dyspnea to 3-month treatment with combined inhaled corticosteroids and long-acting $\beta_{2}$ agonist compared to others. Such a combination of morphologic and physiologic assessments is logical to approach a complex disease like COPD. In this study, we hypothesized that this $\mathrm{CT}$-emphysema index/FEV ${ }_{1}$ approach of phenotyping COPD may predict mortality. In a local cohort of well-characterized stable multiethnic COPD patients followed up in a chest clinic of an urban-based general hospital, we studied the COPD-associated mortality and its risk factors according to these phenotypes. We also compared this approach with that of GOLD 2017 combined assessment.

\section{Patients and methods}

\section{Patient population}

All eligible patients with stable COPD who were referred to or followed up in the chest clinic of the 1,200-bed Penang Hospital, Malaysia, were invited to participate. The inclusion criteria were age $\geq 40$ years old, smoking history of $\geq 10$ pack-years, a diagnosis of COPD by GOLD criteria (inclusive of post-BD FEV $\mathrm{F}_{1}$ forced volume capacity $[\mathrm{FVC}]<0.7$ ), Asian ethnicity, and willingness to undergo study-related testing that included thorax CT. The exclusion criteria were COPD exacerbation within the past 1 month, tuberculosis-destroyed lung (defined as post-tuberculosis scarring involving more than one lung lobe), presence of significant concomitant lung conditions like bronchiectasis or interstitial lung disease, previous lung resection surgery, uncontrolled cancer, and pregnancy. The recruitment began in September 2013. This study forms part of a larger longitudinal cohort study of Asian Network of Obstructive Lung Disease (ANOLD) ${ }^{12}$ that looks at the heterogeneity of COPD. To date, this research network consists of eleven Asian countries. Written informed consent was obtained from all participants. Research and ethical approval was obtained from the National Research and Ethics Committee of Malaysia (NNMR-13-313-15138).

\section{Data collection including mortality}

Demographic and clinical data were collected by a single investigator (OCK) via face-to-face interview and selfadministered questionnaires. The data included respiratory symptoms, spirometry, St George's Respiratory Questionnaire (SGRQ), ${ }^{13}$ breathlessness score (using modified Medical Council Research Scale [mMRC] ${ }^{14}$ ), COPD Assessment Tool (CAT) ${ }_{15}^{15}$ respiratory diagnoses, Charlson's Comorbidity Index,${ }^{16}$ health care utilization, medication use, and COPD risk factors. Spirometry data were obtained before and after administration of a short-acting $\beta$-agonist, and its quality was independently reviewed by ANOLD study coordinating center in Seoul to ensure that American Thoracic Society criteria were met. ${ }^{17}$ Participants were followed up at least once annually on spirometry and mortality. For subjects who died, the specific dates and causes of death were obtained from hospital medical records or family members with verification from official death certificate whenever possible. Death directly due to COPD or recognized COPD-associated comorbidities was considered as COPD-associated death.

\section{QCT measurement}

Objective analysis of the lung parenchyma and airways was performed on volumetric CT scans of thorax at full inspiration using a 64-MDCT scanner (Somaton Sensation 64; Siemens Medical Solutions, Forchheim, Germany) in Loh Guan Lye Specialist Centre, Penang. All CT scans were obtained based on standardized protocol from Research Institute of Radiology, Asan Medical Center in Seoul. ${ }^{18,19}$ Briefly, scan parameters included $0.75 \mathrm{~mm}$ collimation, 100 eff mAs, $140 \mathrm{kVp}$, and pitch 1.0. Patients were scanned craniocaudally in supine position. Images were reconstructed using a soft kernel (B30f; Siemens Medical Solutions) from thoracic inlet to lung base. The CT-emphysema index (or Low Attenuation Area percent) was determined by automatic calculation from the CT data of the volume fraction of the lungs below $-950 \mathrm{HU}$ at full inspiration. Airway dimensions 
including the wall area (WA), lumen area (LA), and WA $(\mathrm{WA} \%)$, defined as $\mathrm{WA} /(\mathrm{WA}+\mathrm{LA}) \times 100$, were measured near the origin of the 4 segmental bronchi $(\mathrm{RB} 1, \mathrm{LBI}+2$, RB10, LB10) using in-house software in Asan Medical Center. Quality of images and compliance to protocol in Penang center were verified by Asan Medical Center prior to commencement of scanning COPD study subjects.

\section{Combined COPD assessment}

Patients were categorized into Groups A-D according to GOLD 2017 classification (refer to GOLD 2017). The cut-off point between high and low risk of future exacerbation was based on previous reported hospitalized exacerbations of two times a year (ie, high risk of exacerbation when $\geq 2$ times a year). The cut-off point between the "more" or "less" symptoms followed the GOLD recommendation of CAT of 10 and mMRC of 2 (whichever is higher) (ie, "more" symptoms when $\mathrm{CAT} \geq 10$ or $\mathrm{mMRC} \geq 2$ ).

\section{Classification into CT-emphysema index/FEV, phenotypes}

Patients were categorized into "mild mixed airwayemphysema," "airway-dominant," "emphysema-dominant," and "mixed airway-emphysema" disease based on CTemphysema index at cut-off points of $15 \%$ (ie, $\geq 15 \%$ for emphysema) and post-BD $\mathrm{FEV}_{1}$ of $50 \%$ predicted normal (ie, $\mathrm{FEV}_{1}$ of $<50 \%$ predicted normal for airway-dominant). ${ }^{11}$ Emphysema is normally considered present when $>10 \%$ of pixels fall below the cut-off values of -910 or $-920 \mathrm{HU}$, depending on slice thickness and the reconstruction algorithm employed. ${ }^{20}$ We used $15 \%$ of $-950 \mathrm{HU}$ as cut-off to distinguish between emphysema and nonemphysema status in our Asian patients based on measurements derived from 48 healthy Korean nonsmokers that showed a -950 HU range between $0.15 \%$ and $13.25 \%$ with a mean of $4.66 \%$ (unpublished data). As such, we are confident that $-950 \mathrm{HU}$ values of $<15 \%$ are compatible with no or trivial emphysema. ${ }^{21,22}$ A cut-off of $\mathrm{FEV}_{1} 50 \%$ predicted normal is based on GOLD 2017 recommendation of severe airflow limitation when $\mathrm{FEV}_{1}$ is $<50 \%$ predicted (GOLD 2017 recommendation).

\section{Statistical analysis}

Standard descriptive analyses were performed on patient baseline characteristics. Kaplan-Meier survival estimates were performed to examine the probability of death with CT-emphysema index/FEV ${ }_{1}$ phenotypes and GOLD 2017 classification. Log rank tests were used to test for differences between groups. Univariate and multivariate Cox proportional hazards analyses were performed to investigate the associations of clinicodemographic indices and CT-emphysema index/FEV ${ }_{1}$ phenotypes with COPD-associated mortality. Proportional-hazards assumption tests were used to ensure that the variables fit the regression models. A $p$-value of $<0.05$ was considered as statistical significant. All analyses were performed using Stata Version 13.1 (Stata Corporation, College Station, TX, USA).

\section{Results}

\section{Baseline patient characteristics}

One hundred and twenty-three patients were recruited. Three declined QCT. Eight subjects' QCT data were not interpretable due to quality issues. Four subjects were lost to follow-up and their survival data were censored till the date of last follow-up visit (follow-up rate, 96.4\%). Final analyzable data were based on 112 subjects. Their baseline characteristics are shown in Table 1. The cohort appeared to represent those with a more severe disease characterized by a mean $\mathrm{FEV}_{1}$ of $46 \%$ predicted normal, frequent exacerbations, and high treatment burden including home oxygen use.

\section{CT-emphysema index/FEV, phenotypes and GOLD classification}

The number (percentage) of patients in each CT-emphysema index/FEV 1 phenotype was as follows: 29 (25.9\%) "mild mixed airway-emphysema" disease, 23 (20.5\%) "airwaydominant," 15 (13.4\%) "emphysema-dominant," and $45(40.2 \%)$ "severe mixed airway-emphysema" disease. The number (percentage) of patients in each GOLD group was as follows: 35 (31.3\%) Group A, 33 (29.5\%) Group B, 7 (6.2\%) Group C, and 37 (33\%) Group D. The relationship between the proportion of patients according to GOLD classification and CT-emphysema index/FEV ${ }_{1}$ phenotypes are shown in a scatterplot (Figure 1). Proportionately more patients of Groups B and D had "severe mixed airwayemphysema" disease while more patients of Group A had "mild mixed" disease.

\section{Mortality data}

The median follow-up time as of June 30, 2017 was 1,000 days ( 2 years and 9 months) (range, 60-1,400 days). Eighteen out of $112(16 \%)$ died during this time. Causes of death were as follows: COPD $(n=8)$, pneumonia $(n=4)$, congestive cardiac failure/coronary artery disease $(n=2)$, lung carcinoma $(n=1)$, stroke $(n=1)$, motor traffic accident $(n=1)$, and intestinal obstruction $(n=1)$. The final 2 causes were considered as 
Table I Baseline patient characteristics $(n=|| 2)$

\begin{tabular}{|c|c|c|}
\hline Characteristics & Value & Range \\
\hline Age, year & $67 \pm 7.4$ & $49-84$ \\
\hline \multicolumn{3}{|l|}{ Gender } \\
\hline Male & $105(93.7)$ & - \\
\hline Female & $7(6.3)$ & - \\
\hline \multicolumn{3}{|l|}{ Ethnicity } \\
\hline Malay & $31(27.6)$ & - \\
\hline Chinese & $73(65.2)$ & - \\
\hline Indians & $8(7.2)$ & - \\
\hline BMI, $\mathrm{kg} / \mathrm{m}^{2}$ & $22 \pm 4.6$ & $13-38$ \\
\hline \multicolumn{3}{|l|}{ Weight classes } \\
\hline Underweight & $17(15.2)$ & - \\
\hline Normal & 47 (4I.9) & - \\
\hline Overweight & $31(27.6)$ & - \\
\hline Obese & $17(15.3)$ & - \\
\hline \multicolumn{3}{|l|}{ Smoking history } \\
\hline Current smoker & $20(17.8)$ & - \\
\hline Former smoker & $92(82.2)$ & - \\
\hline Smoking pack-years & $60.3 \pm 36.5$ & $10-204$ \\
\hline \multicolumn{3}{|l|}{ Spirometry } \\
\hline $\mathrm{FEV}_{1}$, liters & $1.08 \pm 0.46$ & $0.36-2.50$ \\
\hline $\mathrm{FEV}_{1}, \%$ predicted & $45.7 \pm 17.2$ & $16-97$ \\
\hline FVC, liters & $2.04 \pm 0.65$ & $0.55-3.92$ \\
\hline FVC, \% predicted & $62.6 \pm 18.2$ & $23-97$ \\
\hline $\mathrm{FEV}_{1} / \mathrm{FVC}$ ratio & $0.52 \pm 0.10$ & $0.26-0.70$ \\
\hline \multicolumn{3}{|l|}{ Hospitalized// 2 months } \\
\hline None & 38 (33.9) & - \\
\hline $\mathrm{I}-2$ & $44(39.2)$ & - \\
\hline $3-4$ & $24(21.4)$ & - \\
\hline$\geq 5$ & $6(5.3)$ & - \\
\hline \multicolumn{3}{|l|}{ Comorbidities } \\
\hline Ischemic heart disease & $12(10.8)$ & - \\
\hline Congestive cardiac failure & $3(2.7)$ & - \\
\hline Stroke & $4(3.6)$ & - \\
\hline Peptic ulcer disease & $24(21.4)$ & - \\
\hline Diabetes mellitus & $20(18.0)$ & - \\
\hline Chronic renal disease & I $(0.9)$ & - \\
\hline Cancer & $2(1.8)$ & - \\
\hline \multicolumn{3}{|l|}{ Charlson comorbidity index } \\
\hline I & $62(56.3)$ & - \\
\hline 2 & $36(32.7)$ & - \\
\hline$\geq 3$ & $12(10.9)$ & - \\
\hline \multicolumn{3}{|l|}{ Regular therapy } \\
\hline ICS + LABA + LAMA & $32(28.8)$ & - \\
\hline LTOT & II (9.9) & - \\
\hline \multicolumn{3}{|l|}{ GOLD classification } \\
\hline A & $35(31.3)$ & - \\
\hline B & $33(29.5)$ & - \\
\hline $\mathrm{C}$ & $7(6.2)$ & - \\
\hline D & $37(33.0)$ & - \\
\hline \multicolumn{3}{|l|}{ QCT-defined } \\
\hline LAA\% (CT-emphysema index) & $19.7 \pm 14.39$ & $0.1-60.6$ \\
\hline WA\% & $51.3 \pm 9.52$ & $25.8-76.5$ \\
\hline \multicolumn{3}{|c|}{ CT-emphysema index/FEV , phenotypes } \\
\hline Mild mixed disease & $29(25.9)$ & - \\
\hline Predominantly airway & $23(20.5)$ & - \\
\hline Predominantly emphysema & $15(13.4)$ & - \\
\hline Severe mixed disease & $45(40.2)$ & - \\
\hline
\end{tabular}

Note: Data are presented as mean $\pm S D$ or counts (percentage).

Abbreviations: BD, bronchodilator; BMI, body mass index; $C T$, computed tomography; $\mathrm{FEV}_{1}$, post-BD forced expiratory volume in I second; FVC, post-BD forced vital capacity; GOLD, Global Initiative for Chronic Obstructive Lung Disease; ICS, inhaled corticosteroids; LAA\%, low attenuation area percent; LABA, longacting $\beta$-agonist; LAMA, long-acting muscarinic antagonist; LTOT, long-term oxygen therapy; $\mathrm{QCT}$, quantitative $\mathrm{CT}$; WA\%, wall area percent.
non-COPD-associated causes. As such, 16 patients died of COPD-associated death (14.2\%).

\section{Kaplan-Meier survival estimates}

There was significant difference of survival estimates with CT-emphysema index $/ \mathrm{FEV}_{1}$ phenotypes $(p=0.03$, log rank test) but not with GOLD classification $(p=0.08)$. These are shown in Figures 2 and 3.

\section{Cox proportional hazards analyses on predictors of mortality}

All demographic and clinical parameters were entered for univariate analyses. The parameters shown to predict mortality were age, BMI, use of long-term oxygen therapy (LTOT), FEV 1 , FVC, CAT score, SGRQ, CT-emphysema index, and "severe mixed airway-emphysema" disease (compared to "mild mixed" disease) (Table 2).

All indices predictive of mortality on univariate analyses (except for LTOT) were entered into multivariate analyses to investigate the relationship between CT-emphysema index/ $\mathrm{FEV}_{1}$ and mortality. LTOT was not selected as it is primarily a treatment outcome. CT-emphysema index and $\mathrm{FEV}_{1}$ are also not entered into the multivariate model as separate factors since they contribute to the CT-emphysema index/ $\mathrm{FEV}_{1}$ phenotypes. Multivariate analyses showed that only age, BMI, and CAT score remained predictive of COPDassociate mortality (Table 2). In fact, the lack of change of hazard ratios of these three parameters indicates their independence with COPD-associated mortality.

\section{Discussion}

We explored the potential of a novel CT-emphysema index/ $\mathrm{FEV}_{1}$ approach to predict COPD-associated mortality and showed in our cohort that "severe mixed airway-emphysema" had a higher mortality risk than "mild mixed" phenotype. The survival model seems to perform better than GOLD 2017 classification. However, only age, BMI, and CAT score were independently predictive of mortality in multivariate analyses. Our findings of age, BMI, and CAT score as independent predictors of COPD-associated mortality lend support to the existing bulk of evidence of their importance in prognosticating COPD.,3

Our main study limitation is that our cohort size was not powered for mortality analysis. However, it is still plausible that we are encountering a genuine observation and that our current findings can be considered as hypothesis generating. Combining a morphology assessment with a physiologic parameter makes much clinical and research sense to help 


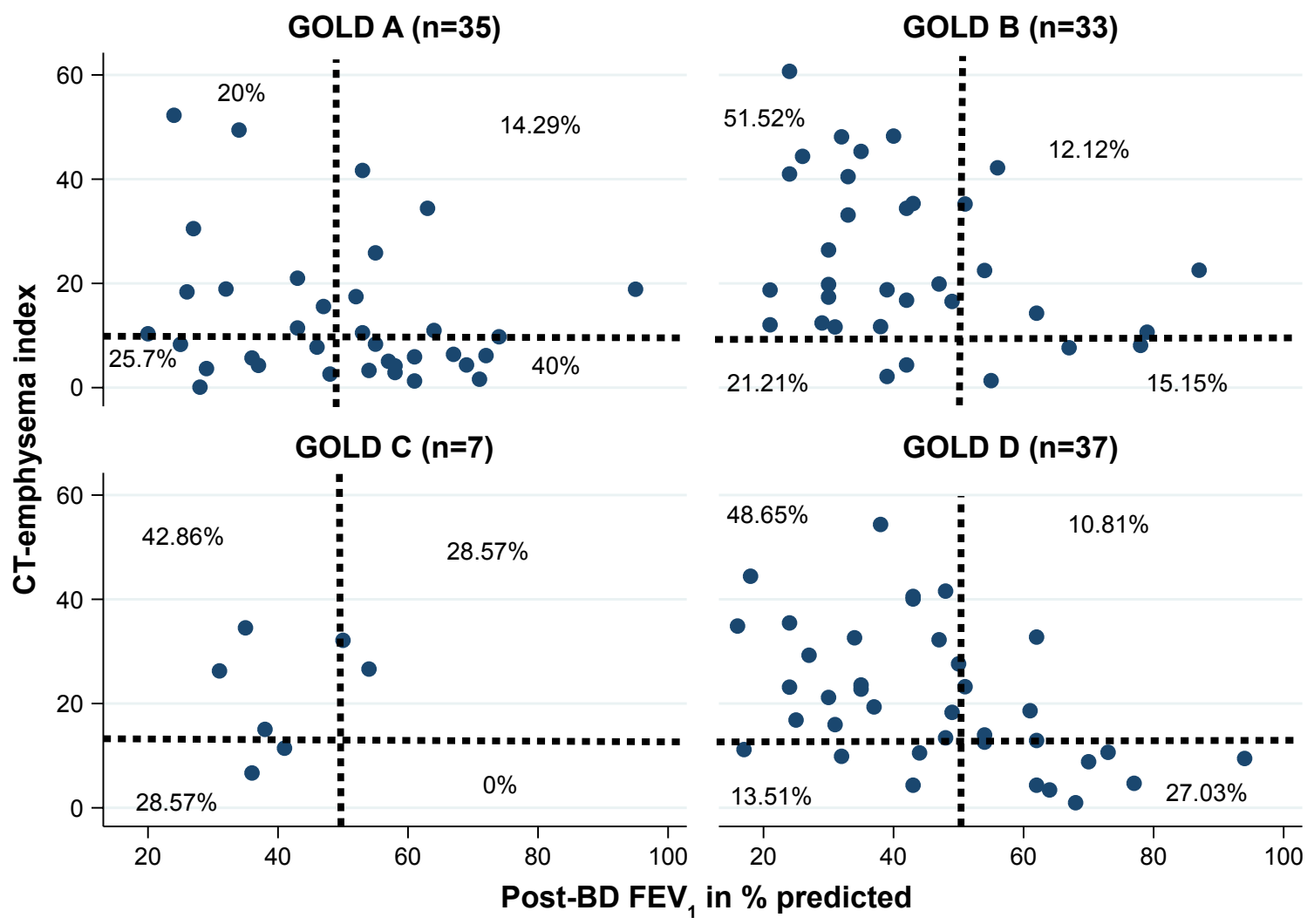

Figure I Scatter plot showing relationships between CT-emphysema index/FEV, COPD phenotypes and GOLD groups among patients ( $\mathrm{n}=\mathrm{I}$ I2).

Note: Right upper quadrant = emphysema-dominant; right lower quadrant = mild mixed airway-emphysema disease; left lower quadrant = airway-dominant; left upper quadrant = severe mixed airway-emphysema.

Abbreviations: BD, bronchodilator; CT, computed tomography; FEV , forced expiratory volume in I second; GOLD, Global Initiative for Chronic Obstructive Lung Disease.

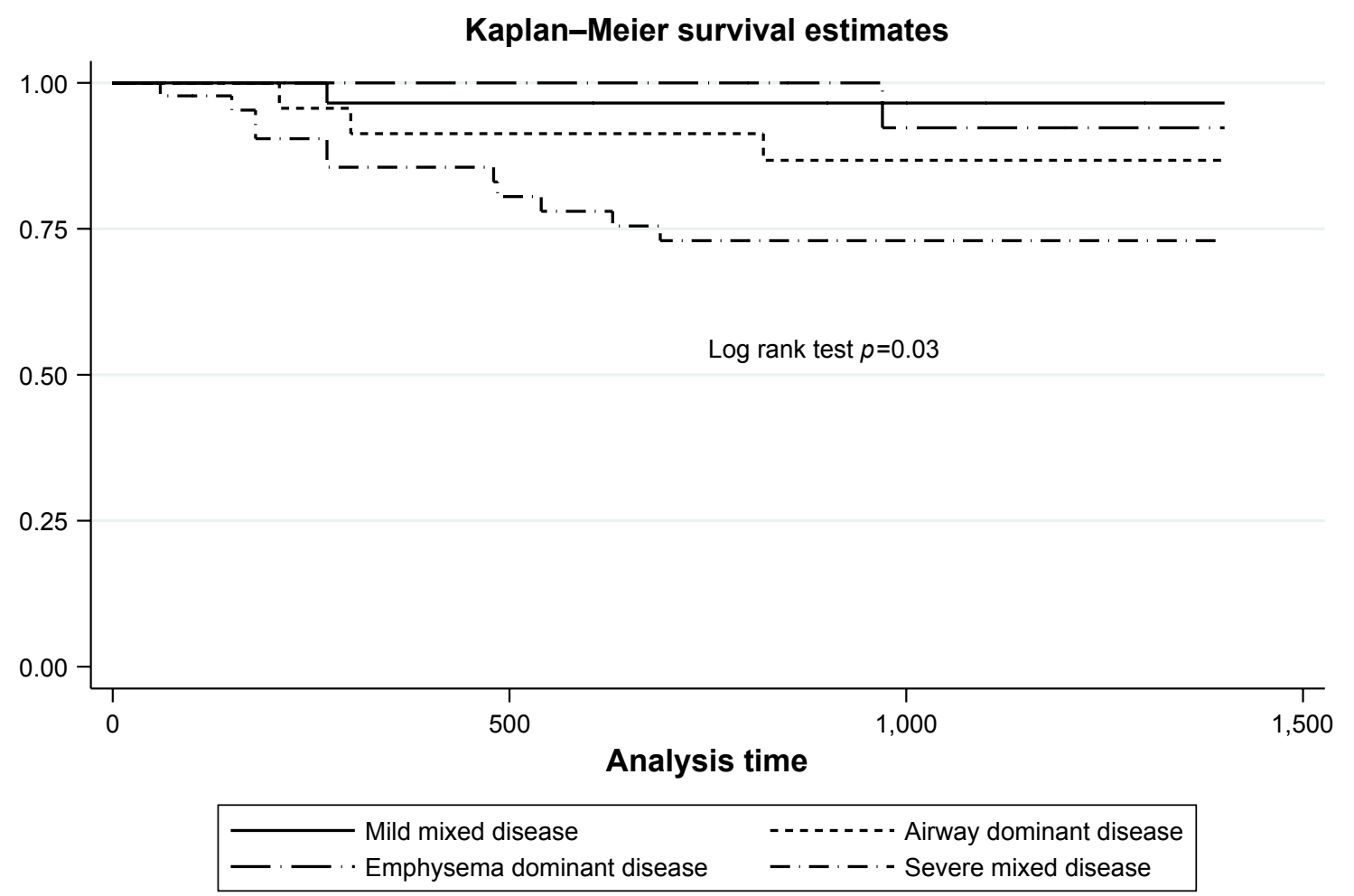

Figure 2 Kaplan-Meier survival probability estimates according to CT-emphysema index/FEV, COPD phenotypes. Abbreviations: $\mathrm{CT}$, computed tomography; $\mathrm{FEV}_{1}$, forced expiratory volume in I second. 


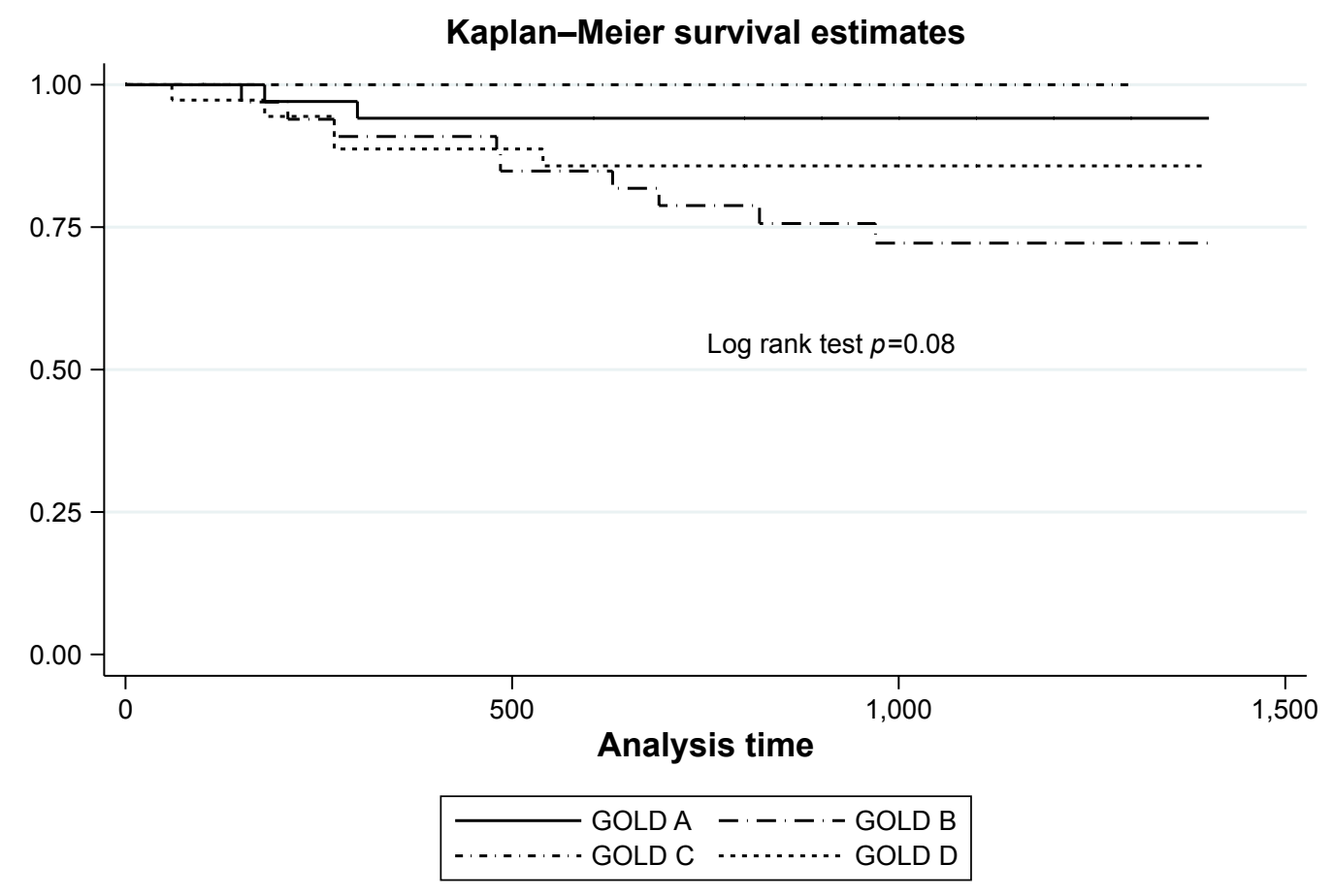

Figure 3 Kaplan-Meier survival probability estimates according to GOLD 2017 groups.

Abbreviation: GOLD, Global Initiative for Chronic Obstructive Lung Disease.

assess a complex disease like COPD. Our preliminary finding from a small local cohort may point toward the relevance of a certain "severe mixed airway-emphysema" disease that carries a worse prognosis. Together with the reports of Lee et al, ${ }^{11}$ this novel QCT/FEV ${ }_{1}$ approach to phenotyping or subtyping COPD may be worth exploring further. Larger sample size studies are obviously necessary to validate this possibility. We hope to compare our findings with other COPD cohorts of the ANOLD network based on this CT-emphysema index/FEV ${ }_{1}$ approach.

Another important study limitation is that we only collected general data on comorbidities, which are not specific enough on severity (eg, those of cardiac failure or diabetes). This may bias our survival results. Also, it should be noted that the discriminative capacity of our $\mathrm{QCT} / \mathrm{FEV}_{1}$ approach (over this period of follow-up) was limited to discriminating those with "severe mixed airway-emphysema" disease from "mild mixed" disease. The other 2 groups had either a different charted course or one in which QCT/FEV 1 approach is not discriminative enough.

We also showed that there was generally a lack of correlation in the distribution of subjects classified under CT-emphysema index/FEV 1 and GOLD 2017 groups. GOLD A group has proportionately more "mild mixed"

Table 2 Predictors in Cox proportional hazard models of COPD-associated mortality

\begin{tabular}{|c|c|c|c|c|}
\hline Parameters & $\begin{array}{l}\text { Crude HR } \\
(95 \% \mathrm{Cl}) \\
\end{array}$ & $p$-value & $\begin{array}{l}\text { Adjusted HR } \\
(95 \% \mathrm{Cl})\end{array}$ & $p$-value \\
\hline Age, years & $1.10(1.02-1.19)$ & 0.013 & I.II (I.02-I.20) & 0.014 \\
\hline $\mathrm{BMI}, \mathrm{kg} / \mathrm{m}^{2}$ & $0.83(0.72-0.95)$ & 0.011 & $0.83(0.70-0.98)$ & 0.036 \\
\hline LTOT & $4.62(1.60-13.35)$ & 0.005 & - & - \\
\hline $\mathrm{FEV}_{1}(\mathrm{~L})$ & $0.16(0.03-0.72)$ & 0.017 & - & - \\
\hline $\mathrm{FVC}(\mathrm{L})$ & $0.37(0.16-0.85)$ & 0.020 & $1.13(0.36-3.50)$ & 0.822 \\
\hline CAT score & $1.08(1.01-1.16)$ & 0.024 & $1.16(1.00-1.34)$ & 0.049 \\
\hline $\mathrm{mMRC}$ & $1.75(1.03-2.98)$ & 0.036 & $0.92(0.36-2.30)$ & 0.862 \\
\hline SGRQ & $1.03(1.00-1.06)$ & 0.027 & $0.98(0.92-1.04)$ & 0.610 \\
\hline Emphysema index & $1.04(1.01-1.07)$ & 0.004 & - & - \\
\hline Severe mixed AE disease (vs normal) & $8.88(1.14-68.8 I)$ & 0.037 & $3.36(0.34-33.08)$ & 0.299 \\
\hline
\end{tabular}

Abbreviations: AE, airway-emphysema; $\mathrm{BD}$, bronchodilator; BMI, mean body mass index; CAT, COPD Assessment Tool; $\mathrm{Cl}, 95 \%$ confidence interval; $\mathrm{FEV}$, post-BD forced expiratory volume in I second; FVC, post-BD forced volume capacity; LTOT, long-term oxygen therapy; mMRC, modified Medical Research Council scale; SGRQ, St Georges Respiratory Questionnaire. 
disease, while GOLD B and D groups have proportionately more "severe mixed" disease. The latter may suggest a morphologic/physiologic similarity (ie, more emphysema and airflow obstruction) of GOLD B and D groups that explain their higher degree of symptoms (compared to A and C groups). This also supports a possible "severe mixed" disease as a relevant COPD phenotype. It is unclear what the prevalence of airway or emphysema-dominant or mixed disease in the general COPD population is. It is likely that its prevalence would vary according to the differing COPD populations and based on geography. In an epidemiology survey of over 1,400 Japanese COPD patients, Tatsumi et $\mathrm{al}^{23}$ showed that $90 \%$ were of emphysema-dominant phenotype based on QCT. Some researchers have shown that emphysema-dominant disease is probably a COPD phenotype that is less responsive to both anti-inflammatory and bronchodilator therapy. ${ }^{24}$ In our cohort, "emphysemadominant" was the least common of the 4 phenotypes.

The mortality rate of COPD patients varies significantly depending on disease severity. In their review, Nishimura and Tsukino ${ }^{25}$ suggested that the 5-year COPD mortality can be as high as $40 \%-70 \%$, a figure that is similar to many malignancies. ${ }^{25}$ The near 4-year absolute mortality rate attributable to COPD was around $14 \%$ in our cohort of moderate-to-severe COPD patients. Preliminary comparison with some ANOLD Asian sites suggests that the mortality rate of our cohort is considered high. This may be due to our COPD cohort having more severe disease.

At the time of writing, the GOLD 2018 guidelines have just been published. It acknowledges that the "ABCD" combined assessment performed no better than the earlier GOLD spirometric classification in predicting mortality or other health outcomes. ${ }^{26}$ Despite this, they suggest that the "ABCD" assessment can still be used to provide therapeutic recommendations and also advised that spirometric assessment will remain vital for diagnosis and prognostication, considering other therapeutic approaches (eg, lung volume reduction surgery) as complement to the GOLD 2017 "ABCD” assessment tool (where $\mathrm{FEV}_{1}$ is dropped). This perhaps explains our observation of our CT-emphysema index/FEV ${ }_{1}$ model predicting mortality better than the GOLD 2017 model.

\section{Acknowledgment}

The authors wish to thank the National Institute of Health, Ministry of Health Malaysia, for the provision of research grant to conduct this study, and Loh Guan Lye Specialist Centre, Penang for providing the service of CT and blood collection for this research. This paper was presented at the 22nd Congress of the Asian Pacific Society of Respirology, Sydney, Australia, November 23-26, 2017 (Oral Presentation, "Late Breaking Findings" Session) and the abstract was published in Respirology. 2017;22(Suppl 3):70-71 (Abstract no AOL 012).

\section{Disclosure}

The authors report no conflicts of interest in this work.

\section{References}

1. Mathers CD, Loncar D. Projections of global mortality and burden of disease from 2002 to 2030. PLoS Med. 2006;3:e442.

2. Celli BR. Predictors of mortality in COPD. Respir Med. 2010; 104(6):773-779.

3. Global Initiative for Chronic Obstructive Lung Disease (GOLD). Global strategy for the diagnosis, management, and prevention of chronic obstructive pulmonary disease. 2017. Available from: http://goldcopd. org/gold-2017-global-strategy-diagnosis-management-preventioncopd/. Accessed December 1, 2017.

4. Coxson HO, Leipsic J, Parraga G, Sin DD. Using pulmonary imaging to move chronic obstructive pulmonary disease beyond FEV . $_{1}$. Am J Respir Crit Care Med. 2014;190(2):135-144.

5. Martinez CH, Chen YH, Westgate PM, et al; COPD Gene Investigators. Relationship between quantitative CT metrics and health status and BODE in chronic obstructive pulmonary disease. Thorax. 2012;67(5): 399-406.

6. Leivseth L, Brumpton BM, Nilsen TIL, Mai XM, Johnsen R, Langhammer A. GOLD classifications and mortality in chronic obstructive pulmonary disease. Thorax. 2013;68(10):914-921.

7. Soriano JB, Lamprecht B, Ramírez AS, et al. Mortality prediction in chronic obstructive pulmonary disease comparing the GOLD 2007 and 2011 staging systems: a pooled analysis of individual patient data. Lancet Respir Med. 2015;3(6):443-450.

8. Lynch DA. Progress in imaging COPD, 2004-2014. Chronic Obstr Pulm Dis. 2014;1(1):73-82.

9. Haruna A, Muro S, Nakano Y. CT scan findings of emphysema predict mortality in COPD. Chest. 2010;138(3):635-640.

10. Schroeder JD, McKenzie AS, Zach JA, et al. Relationships between airflow obstruction and quantitative CT measurements of emphysema, air trapping, and airways in subjects with and without chronic obstructive pulmonary disease. AJR Am J Roentgenol. 2013;201(3):460-470.

11. Lee JH, Lee YK, Kim EK, et al. Responses to inhaled long-acting betaagonist and corticosteroid according to COPD subtype. Respir Med. 2010;104(4):542-549.

12. Loh LC, Oh YM, Lee SD; ANOLD Researchers. Asian Network for Obstructive Lung Disease (ANOLD)-COPD from an Asian perspective. QJM. 2015;108(12):921-922.

13. Jones PW, Quirk FH, Baveystock CM. The St George's respiratory questionnaire. Respir Med. 1991;85(Suppl B):25-31.

14. Celli BR, Cote CG, Marin JM, et al. The body-mass index, airflow obstruction, dyspnea, and exercise capacity index in chronic obstructive pulmonary disease. $N$ Engl J Med. 2004;350(10):1005-1012.

15. Jones PW, Harding G, Berry P, Wiklund I, Chen WH, Kline Leidy N. Development and first validation of the COPD Assessment Test. Eur Respir J. 2009;34:648-654.

16. Charlson ME, Pompei P, Ales KL, MacKenzie CR. A new method of classifying prognostic comorbidity in longitudinal studies: development and validation. J Chronic Dis. 1987;40(5):373-383.

17. American Thoracic Society. Standardization of spirometry, 1994 update. Am J Respir Crit Care Med. 1995;152(3):1107-1136.

18. Lee YK, Oh YM, Lee JH, et al; KOLD Study Group. Quantitative assessment of emphysema, air trapping, and airway thickening on computed tomography. Lung. 2008;186(3):157-165. 
19. Yoo JW, Hong Y, Seo JB, et al. Comparison of clinico-physiologic and CT imaging risk factors for COPD exacerbation. J Korean Med Sci. 2011;26(12):1606-1612.

20. Friedman PJ. Imaging studies in emphysema. Proc Am Thorac Soc. 2008;5:494-500.

21. Boschetto P, Miniati M, Moiotto D, et al. Predominant emphysema phenotype in chronic obstructive pulmonary disease patients. Eur Respir J. 2003;21(3):450-454.

22. Miniati M, Filippi E, Falaschi F, et al. Radiologic evaluation of emphysema in patients with chronic obstructive pulmonary disease: chest radiography versus high resolution computed tomography. Am J Respir Crit Care Med. 1995;151(5):1359-1367.

23. Tatsumi K, Kasahara Y, Kurosu K, et al; Respiratory Failure Research Group in Japan. Clinical phenotypes of COPD: results of a Japanese epidemiological survey. Respirology. 2004;9(3):331-336.
24. Miravitlles M, Calle M, Soler-Cataluña JJ. Clinical phenotypes of COPD: identification, definition and implications for guidelines. Arch Bronconeumol. 2012;48(3):86-98.

25. Nishimura K, Tsukino M. Clinical course and prognosis of patients with chronic obstructive pulmonary disease. Curr Opin Pulm Med. 2000; 6(2):127-132.

26. Global Initiative for Chronic Obstructive Lung Disease (GOLD). 2018 Global strategy for prevention, diagnosis and management of COPD. 2018. Available from: http://goldcopd.org/wp-content/uploads/2017/11/ GOLD-2018-v6.0-FINAL-revised-20-Nov_WMS.pdf. Accessed January 10, 2018.

\section{Publish your work in this journal}

The International Journal of COPD is an international, peer-reviewed journal of therapeutics and pharmacology focusing on concise rapid reporting of clinical studies and reviews in COPD. Special focus is given to the pathophysiological processes underlying the disease, intervention programs, patient focused education, and self management protocols.

\section{Dovepress}

This journal is indexed on PubMed Central, MedLine and CAS. The manuscript management system is completely online and includes a very quick and fair peer-review system, which is all easy to use. Visit http://www.dovepress.com/testimonials.php to read real quotes from published authors.

Submit your manuscript here: http://www.dovepress.com/international-journal-of-chronic-obstructive-pulmonary-disease-journal 